\title{
Interfaces textuais em \\ O Evangelho Segundo Jesus Cristo, de José Saramago
}

\author{
Delzi Alves Laranjeira \\ Universidade Federal de Minas Gerais
}

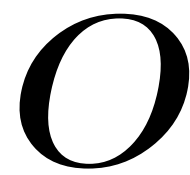

Evangelho Segundo Jesus Cristoé uma reescrita ficcionalizada da vida de Jesus baseada nos Evangelhos canônicos.

O próprio título do romance instaura a conexão com o texto bíblico, fazendo dele seu intertexto mais óbvio e direto. O texto de Saramago, porém, não se limita a dialogar com os evangelhos: ele apresenta ao leitor um verdadeiro mosaico de citações e referências que, recontextualizadas, operam, na maioria das vezes, como elementos de ruptura e subversão em relação à mensagem doutrinária contida nos evangelhos canônicos.

A noção de intertextualidade, embora tenha surgido por volta dos anos 60, mais precisamente da maneira como a definiu Julia Kristeva em seu ensaio "Problèmes de la structuration du texte", é um fenômeno antigo, e teorias sobre a intertextualidade são encontradas "onde quer que existam discursos sobre textos". ${ }^{1}$ Assim, reflexões em direção a uma teoria intertextual podem ser traçados desde Platão, Aristóteles, Longino, Erasmo, Montaigne, culminando, no século 20, com as teses propostas por Bakhtin, Borges, T. S. Eliot, Harold Bloom, Kristeva e Michael Riffaterre. Nessas teorias, subjaz a idéia de que um texto não existe como um todo separado, auto-suficiente e hermético. ${ }^{2}$

\footnotetext{
${ }^{1}$ STILL e WORTON, 1993. p. 2.

${ }^{2}$ STILL e WORTON, 1993. p.1. A noção de texto aqui é vista num sentido mais amplo, como um sistema de significação. Dentro de um contexto mais tradicional da crítica literária, como a Nova Crítica, a definição de texto é mais restrita, e ele pode ser enquadrado dentro de um sistema fechado, significando per si, independente de qualquer referência exterior.
} 
Assim, outros textos, outros autores, outros leitores, outros contextos (históricos, sociais) sempre operam para desestabilizar quaisquer tentativas de fechamento. Vejamos então como ocorre em $O$ Evangelho Segundo Jesus Cristo esse diálogo com outros textos e como eles contribuem para construir a dessacralização do texto bíblico, ao enfatizar quão demasiado humana (no sentido de ser um construto) e não divina é a história de Jesus.

O romance se inicia com a crucificação de Jesus. O diálogo intertextual é instaurado com a utilização de uma gravura, que, a medida que vai sendo descrita e comentada, compõe a tradicional cena do Cristo crucificado entre os dois ladrões. A crucificação aparece aos olhos do leitor através da gravura, não como uma mera descrição, mas como uma interpretação que evoca além do texto evangélico, que sobretudo enfatiza a imagem fabricada pelo artista. Mesmo ao leitor que não conheça a gravura utilizada - da série "A Grande Paixão" do renascentista alemão Albrecht Dürer - é possível inferir que está diante de uma imagem (construída por palavras) que se refere à outra, uma vez que o narrador o coloca consciente desse fato, ao dizer: "o que temos diante de nós é papel e tinta, mais nada" - uma dupla referência: à gravura e ao próprio texto - e também a frase em que menciona o artista: "obviamente, serviu ao gravador para aclarar o tom geral da cabeleira representada”. ${ }^{3}$ O intertexto é explicitamente mencionado, fato que contribui para uma maior percepção do diálogo entre texto escrito e obra de arte que opera no romance.

Em $S / Z$ Roland Barthes propõe o fim das relações hierárquicas instituídas entre literatura e artes plásticas e, que ao eliminar as diferenças que para ele são "puramente de meio material", ${ }^{4}$ renunciase à pluralidade das artes e afirma-se a pluralidade dos textos. As diferentes manifestações artísticas nivelam-se como textos, compondo uma imensa teia que estabelece conexões e diálogos.

\footnotetext{
${ }^{3}$ SARAMAGO, 1997. p. 13,16.

${ }^{4}$ BARTHES, 1974. p. 55.
} 
Julia Kristeva observa que um "texto literário não é um fenômeno isolado, mas é feito de um mosaico de citações, e que qualquer texto é a absorção e transformação de outro". ${ }^{5}$ Para Michael Riffaterre, "[u]m intertexto é um ou mais textos que o leitor deve conhecer de modo a entender uma obra literária em termos de sua significação total" . ${ }^{6}$ A gravura de Dürer, dentro das concepções vistas acima, funciona como hipotexto - o pré-texto, como define Gérard Genette, sobre o qual Saramago construirá a narrativa, que absorve ao mesmo tempo que modifica seu intertexto. ${ }^{7}$

Saramago começa a descrição da gravura pela figura do sol, do lado esquerdo de quem olha, a seguir para o que está abaixo dela, e continua nessa ordem até a passagem para o lado direito, subindo até encontrar a lua para finalmente deter-se na imagem de Jesus, situada ao centro. Além da descrição, há os comentários do narrador, que interferem tanto no texto bíblico quanto na imagem. Assim, o sol é um rosto de homem que chora, como Dürer o compôs, mas sua dor é "uma dor que não remite, lançando pela boca aberta um grito que não poderemos ouvir, pois nenhuma dessas coisas é real". ${ }^{8}$ Nessa frase está contida a referência à gravura - papel e tinta, mais nada - , que já revela ao leitor, em sua função representativa, o momento congelado pelo artista: o sol grita, mas não o podemos ouvir, só imaginar o grito sinalizado pela boca aberta. O texto segue suplementando a imagem, apresentando seu conteúdo e fazendo comentários, reinterpretando, mostrando, através da linguagem verbal o que não está representado nem em Dürer, nem tampouco nos evangelhos.

Um exemplo é a descrição da mulher que se supõe ser Madalena. Apesar de consciente da falta de cores da gravura, ao descrever os cabelos da mulher o narrador os supõe louros: "[t]al

${ }^{5}$ CUDDON, 1991. p. 454.

${ }^{6}$ RIFFATERRE, 1993. p. 56.

7 GENETTE, 1982. p. 11.

${ }^{8}$ SARAMAGO, 1997. p. 13. 
como a primeira trindade de mulheres, mostra os longos cabelos soltos, caídos pelas costas, mas estes têm todo o ar de serem louros, se não foi por pura casualidade a diferença do traço, mais leve nesse caso e deixando espaços vazios no sentido das madeixas". ? A definição da cor do cabelo servirá para uma discussão à respeito do comportamento da mulher tendo como base se é loura ou morena, insinuando o narrador que, sendo essa a verdadeira Madalena, o cabelo louro seria um indicativo de seu passado de pecadora. Com essa comparação, supõe ser a outra mulher, a primeira do lado esquerdo de quem olha, morena de cabelos pretos, distinção que a gravura em si não é capaz de demonstrar ao espectador, e precisa ser construída na fala do narrador.

Na comparação entre o bom ladrão e o mau ladrão, a presença da cor também se constituirá como elemento de distinção. Na gravura, o bom ladrão se encontra, não por acaso, do lado do sol, o lado direito e iluminado e o mau ladrão no lado esquerdo, o lado da lua, em fase crescente, ainda escura. Está presente toda uma simbologia do bem e do mal, "o sol, figura masculina, que irradia luminosidade e calor (...) a lua, figura feminina, fonte de escuridão, sinônimo de trevas, perversidade e apego às coisas terrenas". ${ }^{10}$ Dürer posicionou o bom ladrão e o mau no lugar a que a tradição cristã os relegou, mas a leitura de Saramago questionará essa posição, como no trecho em que descreve o mau ladrão, comparando-o ao outro:

lá em cima, no lugar dos ninhos, levanta ao ar um segundo homem nu, atado e pregado como o primeiro [o bom ladrão], mas este é de cabelos lisos, deixa pender a cabeça para olhar, se ainda pode, o chão, e a sua cara, magra e esquálida, dá pena, ao contrário do ladrão do outro lado, que mesmo no transe final, de sofrimento agónico, ainda tem valor para mostrar-nos um rosto que facilmente imaginamos rubicundo, corria-lhe bem a vida quando roubava, não obstante a falta que fazem as cores aqui. ${ }^{11}$

\footnotetext{
9 SARAMAGO, 1997. p. 16.

${ }^{10}$ FLORES, 1999. p. 98.

${ }^{11}$ SARAMAGO, 1997. p. 17.
} 
Subvertendo tanto a mensagem dos evangelhos, quanto a gravura de Dürer, a narrativa de Saramago usa a ironia para se referir ao bom ladrão - sua face corada, aí indicando não a plenitude celestial que Dürer muito provavelmente quis expressar, mas um reflexo que a boa vida como ladrão lhe proporcionava. Continuando a descrição do mau ladrão, a narrativa o coloca como "homem rectíssimo afinal, a quem sobrou consciência para não fingir acreditar, a coberto de leis divinas e humanas, que um minuto de arrependimento basta para resgatar uma vida inteira de maldade ou uma simples hora de fraqueza". ${ }^{12}$ O texto de Saramago recusa-se a coadunar com o texto bíblico e com a gravura, apresentando um outro julgamento dos dois ladrões, sugerindo que o mau ladrão foi menos hipócrita em se deixar levar por um falso arrependimento, o que teria ocorrido com o bom ladrão.

O texto que descreve Jesus na cruz segue praticamente passo a passo o Cristo de Dürer: fala dos raios que lhe saem da cabeça, a coroa de espinhos, a ausência de descanso para os pés, o corpo suspenso na cruz, a presença dos ossos ao pé da cruz: o crânio, a tíbia e a omoplata. Não há comentários sobre a face ou a expressão de Jesus, o que não deixa de ser curioso, uma vez que as demais personagens presentes na gravura tiveram seus rostos descritos e comentados. Antes da descrição do corpo de Jesus na cruz, o narrador comenta sobre a ação de Jesus absolver o bom ladrão e condenar o mau, acrescentando que ele o fez "por não compreender que não há nenhuma diferença entre um e outro, ou se diferença há, não é essa, pois Bem e o Mal não existem em si mesmos, cada um deles é somente a ausência do outro". ${ }^{13}$ Esse comentário enfatiza, mais uma vez, a posição subversiva que o texto assume em relação aos dogmas cristãos, ao questionar um ato de Jesus e também introduzir uma outra maneira de relacionar Bem e Mal, evitando a polarização estabelecida pela doutrina religiosa, onde a presença do Bem automaticamente exclui a do Mal e vice-versa. Já segundo Saramago, se Bem e Mal

\footnotetext{
12 SARAMAGO, 1997. p. 17.

13 SARAMAGO, 1997. p. 18.
} 
se definem pela ausência do outro, então ambos coexistem, não se excluindo jamais. Não há, portanto Bem ou mal, mas Bem $e$ Mal. Estabelecer que o mal possa existir em Deus, Jesus ou Maria, por exemplo e que o Bem está presente na figura de Satã representa uma postura que bate de frente com a ortodoxia cristã.

Os ossos ao pé da cruz também foram considerados além do sentido óbvio, que é simbolizar o fim, o estágio último da morte, além da clara referência à palavra Gólgota, que significa crânio. O texto ainda acrescenta serem aqueles os ossos de Adão, "subidos do negrume profundo das camadas geológicas arcaicas", ${ }^{14}$ condenados a contemplar eternamente a terra. O capítulo termina com o comentário final sobre o homem que se afasta segurando um balde e uma vara, dizendo que ele será para sempre vítima de uma calúnia, por ter oferecido vinagre a Jesus quando este disse que tinha sede. Na verdade, segundo o narrador, ele ofereceu uma mistura de água e vinagre, "refresco dos mais soberanos para matar a sede, como ao tempo se sabia e praticava". ${ }^{15}$ Os evangelhos dão uma conotação negativa a esse fato, interpretando o oferecimento do vinagre - não há referência á mistura de água e vinagre, como nos revela o narrador - como mais uma maldade feita a Jesus pelos soldados romanos. Dürer reinterpretou essa passagem ao mostrar o homem do balde e da vara como um homem comum; pelos menos suas roupas não o identificam como um soldado, à maneira dos que estão montados nos cavalos ou disputando o manto. Em O Evangelho SegundoJesus Cristo, José Saramago vai além ao reverter o julgamento que a história cristã fez do soldado que ofereceu vinagre, colocando seu ato como sendo de caridade, para aliviar "as securas mortais dos três condenados, e não fez diferença entre Jesus e os Ladrões, pela simples razão de que tudo isso são coisas da terra, que vão ficar na terra, e delas se faz a única história possível". ${ }^{16}$ Com essa sentença o narrador encerra a cena da crucificação da gravura e o capítulo, e dá início à "história

\footnotetext{
${ }^{14}$ SARAMAGO, 1997. p. 19.

15 SARAMAGO, 1997. p. 20.

16 SARAMAGO, 1997. p. 20.
} 
possível" de Jesus, uma história na qual não haverá anjos à sua volta na cruz, nem tampouco um bom ladrão e outro mau, as mulheres que Dürer colocou ao pé da cruz não serão mencionadas e Jesus morrerá pedindo aos homens que perdoem Deus, porque ele não sabe o que faz. Uma cena, sem dúvida, muito diferente da que a tradição relegou a Dürer para que compusesse a gravura.

O afastamento voluntário dos canônicos e a escolha de uma obra que funde o pagão e o cristão, o sagrado e o profano, o humano e o divino para iniciar seu evangelho são usados para anunciar, segundo Maria da Conceição Flores "o evangelho em que irá ser privilegiado um Jesus homem". ${ }^{17}$ Dessa maneira, a gravura de Dürer configura-se, ao mesmo tempo, como "o código e a decifração do romance, pois a escrita e a gravura são irmãs na arte de re/apresentar, através das convenções que lhe são inerentes, o que o artista deseja". ${ }^{18}$ Ao explorar a gravura, Saramago integrou-a na perspectiva de humanização que o romance aponta

Além do diálogo com as artes plásticas, ${ }^{19}$ há no romance muitas referências e citações das Escrituras. Na maioria das vezes, essas citações e alusões são deslocadas de seu contexto bíblico e reinterpretadas em outras situações. Um bom exemplo desse fato é a passagem que narra o encontro entre Jesus e Madalena. Antes, durante e depois de seu encontro amoroso, frases extraídas do Cântico dos Cânticos são utilizadas, muitas vezes para compor a fala das personagens ou expressar seus pensamentos e sentimentos.

A primeira será dita por Jesus quando ele, admirado pela beleza de Madalena, diz-lhe: "Os teus cabelos são como um rebanho de cabras descendo das vertentes pelas montanhas de Galaad". ${ }^{20}$ Já na cama, ao contemplar a nudez de Madalena, Jesus imediatamente

${ }^{17}$ FLORES, 1999. p. 103.

${ }^{18}$ FLORES, 1999. p. 102.

${ }^{19}$ Além da gravura de Dürer, há outros dois trechos do romance, nas páginas 128 e 418 que, segundo Salma Ferraz (1996. p. 33) "guardam profundas relações com, respectivamente, A Madona da Serpentee SãoJoão Batista, de Caravaggio".

${ }^{20}$ SARAMAGO, 1997. p. 281. 
soube o que em verdade queriam dizer aquelas palavras do rei Salomão, As curvas dos réus quadris são como jóias, o teu umbigo é uma taça arredondada, cheia de vinho perfumado, o teu ventre é um monte de trigo cercado de lírios, os teus dois seios são como filhinhos gémeos de uma gazela. ${ }^{21}$

Essa passagem encontra-se no capítulo 7, 2-4 do Cântico dos Cânticos, uma coleção de poemas que, acredita-se, destinavam-se originariamente às solenidades nupciais. Os judeus, entretanto, alegorizaram seu sentido literal claramente erótico, considerando-os como um cântico de amor de Deus para com seu povo escolhido. Mais tarde os cristãos, criariam uma nova alegoria, entendendo o poema como o relacionamento entre Cristo e sua Igreja ou, dependendo de quem interpreta, Cristo e o que nele crê. Já Saramago usa o sentido literal, portanto erótico, do Cântico, para colocá-lo na boca de Jesus, que está prestes a conhecer os prazeres sensuais. Assim, num outro diálogo mais adiante, o Cântico dos Cânticos será novamente mencionado, quando Madalena diz a Jesus: "A minha vida, nesta hora, és tu, Porque, Respondo-te com as palavras do Rei Salomão: o meu amado meteu a mão pela abertura da porta e o meu coração estremeceu". ${ }^{22}$ Essa frase encontra-se no Ct 5,4 na parte que descreve o sonho da esposa com o seu amado. Uma outra citação direta dos Cânticos será feita no capítulo seguinte, quando Jesus deixa Madalena e dirige-se a sua casa em Nazaré: "Confortai-me com uvas passas, fortalecei-me com maçãs porque desfaleço de amor, esta doce verdade poderia vir dize-la Jesus a sua mãe e seus irmãos ..." ${ }^{23}$ Essa passagem está em Ct 2,5, onde o rei dialoga com sua esposa e ela fala: "Restaurou-me com tortas de uvas, fortaleceu-me com maçãs porque estou enferma de amor". ${ }^{24}$ Os versos do Cânticos dos Cânticos são utilizados no romance para enfatizar a união amorosa e carnal de

\footnotetext{
${ }^{21}$ SARAMAGO, 1997. p. 282.

22 SARAMAGO, 1997. p. 284. Grifo meu.

23 SARAMAGO, 1997. p. 291.

${ }^{24}$ BÍBLIA Sagrada, 1993. p. 827.
} 
Jesus e Madalena. A idéia de que o poema remete ao relacionamento entre Deus e Israel ou Jesus e a Igreja Cristã é descartada nas citações do romance: o Cântico é um poema erótico, celebra a união carnal de dois amantes e é nesse contexto que ele é utilizado. Nem por um momento a referência a uma transcendência divina é mencionada: pelo contrário, a ênfase é justamente no amor passional e humano de Madalena e Jesus.

Outras citações do texto bíblico são utilizadas ao longo do romance, sempre recontextualizadas. Salma Ferraz identifica várias passagens do Evangelho Segundo Mateus. ${ }^{25}$ A primeira pode ser identificada na página 218, quando o narrador, ao falar sobre os túmulos das crianças mortas no massacre ordenado por Herodes cita Mateus 2,18: "É Raquel que chora seus filhos, e não quer ser consolada, porque já não existem”. Esse trecho, que aparece primeiro em Jeremias 31,15, é citado por Mateus para se referir ao cumprimento das profecias de Jeremias e à dor das mulheres que perderam seus filhos na matança, da qual Jesus escapou por interferência divina.

No romance, esse episódio é crucial tanto para a vida de José, pai de Jesus, quanto para ele próprio, pois a culpa que perseguia José por não ter alertado as pessoas em Belém sobre a matança foi transferida para Jesus, através dos pesadelos que José tinha e que, após sua morte, passaram a ocorrer com Jesus. Diferentemente do episódio narrado no evangelho de Mateus, o José de O Evangelho Segundo Jesus Cristo foi alertado sobre a matança por acaso, ao escutar os soldados de Herodes discutindo a ordem dada pelo rei. Imediatamente, ele fugiu com Maria e Jesus, deixando as outras crianças entregue à própria sorte. Em Mateus não há comentários sobre o ato de José, nem tampouco um julgamento, e é nisso que o romance mais uma vez diverge do texto bíblico: durante todo o tempo fica patente a idéia de que José procedeu mal em não alertar os outros pais, que cometeu um ato monstruoso, que permitiu a morte de crianças inocentes. A citação sobre Raquel reveste-se de uma conotação irônica, ao sugerir que pelo menos aquela profecia poderia ter sido evitada.

${ }^{25}$ FERRAZ, 1996. p. 24-26. 
Outra citação bíblica ocorre na página 204, quando Jesus se encontra faminto em Jerusalém. Seu dinheiro foi roubado e ele não sabe o que fazer para obter alimento. Comparando a vida da cidade com a do campo, o narrador cita uma passagem do Levítico 19, 9-10:

pois a vida de cidade não é como a boa-vai-ela de andar assobiando pelos campos à mira do que neles teriam deixado os lavradores que cumprem as leis do Senhor, verbi gratia, Quando procederes à ceifa do teu campo, e te esqueceres de algum feixe, não voltes atrás para o levar, quando varejares as tuas oliveiras, não voltes a colher o resto que ficou nos galhos, quando vindimares a tua vinha, não rabisques o que ficou, a tudo isto deverás deixar para que o recolham o estrangeiro, o órfão e a viúva, lembra-te de que foste escravo na terra do Egipto $^{26}$

Mais uma vez, o contexto bíblico é desvirtuado através da citação, que mostra que no campo sempre se deve deixar um resto da colheita para quem necessitar, ao passo que na cidade não há tal solidariedade, ou seja, as leis de Deus não são estritamente cumpridas como manda a palavra sagrada, nem mesmo na cidade considerada sua "moradia terrestre" o que enfatiza um descompasso entre a vontade divina e as ações humanas.

Uma intenção satírica em relação ao texto bíblico manifestase novamente à página 402, quando Jesus cura um paralítico, passagem narrada em Mateus 9, 5-6. Jesus diz ao paralítico que seus pecados estão perdoados, e é questionado pelos fariseus, que alegam que só Deus tem o poder de perdoar. Jesus então retruca: "Qual é mais fácil, dizer ao paralítico Os teus pecados te são perdoados, ou dizer-lhe Levanta-te, toma o teu catre e anda". ${ }^{27}$ A seguir, para demonstrar o poder que possui, cura o aleijado, ordenando-lhe que se levante e leve seu catre para casa. Ao comentar o episódio, o narrador observa que o paralítico pôs-se de pé, "ainda por cima recuperado das forças, apesar da inação causada pela paralisia”. Essa

\footnotetext{
${ }^{26}$ SARAMAGO, 1997. p. 204. Grifo meu.

${ }^{27}$ SARAMAGO, 1997. p. 402.
} 
observação questiona, de uma certa maneira, o milagre, coloca-o sob uma perspectiva científica, na qual é sabido que uma pessoa que perdeu a capacidade de locomover as pernas por um longo tempo acaba por atrofiá-las, que não é possível que tão logo recupere a capacidade de andar, possa fazê-lo sem problemas. Nos Evangelhos, esses fatos são milagres, inquestionáveis sob quaisquer ângulos, e é essa premissa que é atacada no romance.

O maior milagre de Jesus, a ressurreição de Lázaro, que simboliza a vitória contra a morte não acontece em O Evangelho Segundo Jesus Cristo: Maria Madalena impede que Jesus dê a Lázaro a derradeira ordem. O episódio é narrado em Jo 11, 1-44 e é de grande importância na narrativa evangélica porque consolida a idéia de um Jesus imbuído do espírito e poder de Deus, um Jesus capaz de vencer a morte. Em O Evangelho Segundo Jesus Cristo, toda essa idéia também perpassa o Jesus do romance, quando ele diz à Marta: "Teu irmão há-de ressuscitar", e ela responde: "Eu sei que há-de ressuscitar na ressurreição do último dia". ${ }^{28}$ Sentindo-se capaz de tudo fazer por ser o filho de Deus, de ressuscitar Lázaro porque Deus o quer, Jesus estende os braços para dar a ordem suprema: "Lázaro, vem para fora" 29 (Jo 11, 43), mas, como nos conta o narrador, "é nesse instante, em verdade último e derradeiro, que Maria de Magdala põe uma mão no ombro de Jesus e diz, Ninguém na vida teve tantos pecados que mereça morrer duas vezes, então Jesus deixou cair os braços e saiu para chorar". ${ }^{30}$ Madalena torna-se assim, responsável pelo grande milagre que não houve. Jesus escutou a ela, e não a Deus, seu pai, que o autorizava a realizar o grande feito. De uma certa forma, Jesus rebelou-se também contra o Deus medonho, que lhe usava para reafirmar seu poder universal. Entre o pai todo poderoso e a mulher que amava, Jesus optou pela sensatez das palavras de Madalena, e isso não pode deixar de ser interpretado como uma

\footnotetext{
${ }^{28}$ SARAMAGO, 1997. p. 428.

${ }^{29}$ BÍBLIA Sagrada, 1993. p. 1400.

${ }^{30}$ SARAMAGO, 1997. p. 428.
} 
valorização de suas idéias e opiniões. No que se refere ao episódio de Lázaro, Madalena, e não Deus, é quem triunfa.

As citações e referências contidas no romance, contudo, vão muito além do texto bíblico que lhe serve de base: os Evangelhos apócrifos também são utilizados como intertexto. Salma Ferraz identifica várias passagens do romance que estão diretamente relacionadas com os escritos dos apócrifos. ${ }^{31}$ A parteira Zelomi, por exemplo, que auxilia Maria no parto de Jesus, é uma alusão à parteira hebréia Salomé presente na narrativa do Proto Evangelho de Tiago. Ainda desse apócrifo, segundo Ferraz é mencionada a "esterilidade dos pais de Maria, bem como seus nomes (Joaquim e Ana)"32 e a informação de que Jesus nasceu numa gruta ou caverna, e não numa estrebaria. Um episódio narrado no Evangelho Pseudo Tomé, no qual Jesus fabrica uns passarinhos de barro e depois ordena que voem é readaptado no romance na passagem da incredulidade de Tomé, ${ }^{33}$ que quer uma prova de que Jesus é realmente filho de Deus. Jesus então molda os pássaros com barro e joga-lhes uma rede por cima, e pede a Tomé que a retire. Tomé argumenta que os pássaros são de barro e não fugirão, mas tão logo retira a rede, eles saem a voar

Ainda com base nos apócrifos é mencionada "a pouca habilidade do carpinteiro José”, ${ }^{34}$ presente no Evangelho Árabe da Infância. A predileção de Jesus por Madalena é explicitamente mencionada no Evangelho Apócrifo Segundo Felipe, e nos evangelhos gnósticos Madalena também é valorizada, abordagem que também é feita no romance, que destaca Madalena mais do que Maria, contrariando toda uma tradição que cultua Maria como exemplo de pureza perfeita e Madalena como pecadora arrependida. A existência dos irmãos de Jesus não é mencionada nos canônicos, mas é "uma constante em todos os Evangelhos Apócrifos"35 e a informação é

\footnotetext{
${ }^{31}$ FERRAZ, 1996. p. 26.

32 FERRAZ, 1996. p. 27.

33 SARAMAGO, 1997. p. 398-399.

${ }^{34}$ FERRAZ, 1996. p. 27.

35 FERRAZ, 1996. p. 28.
} 
utilizada no romance, que aponta oito irmãos de Jesus: Tiago, Lísia, José, Judas, Simão, Lídia, Justo e Samuel.

A utilização de informações dos Evangelhos canônicos bem como dos apócrifos aponta para uma relação de igualdade entre eles, no sentido de que possuem o mesmo valor como textos que constróem a história de Jesus. No final do primeiro capítulo, ao comentar o ato do homem que oferece vinagre e água para aliviar a sede de Jesus e os outros dois crucificados, o narrador diz que o homem "não fez diferença entre Jesus e os Ladrões, pela simples razão de que tudo isso são coisas da terra, que vão ficar na terra, e delas se faz a única história possível". ${ }^{36}$ Assim, a história que surge tanto nos Evangelhos canonizados quanto nos Apócrifos são consideradas "coisas da terra”, coisas dos homens, construídas pelos homens. Elimina-se a premissa que sustenta e distingue os canônicos dos apócrifos, considerando os primeiros inspirados por Deus e sagrados e os segundos obras de autenticidade duvidosa, espúrios, ou suspeitos de heresia. ${ }^{37}$ Canônicos e apócrifos são textos que constróem a história possível de Jesus, são - com O Evangelho Segundo Jesus Cristo - tentativas de apreender e compreender o advento cristão.

As interfaces textuais no romance também incluem referências a outros textos fora da esfera religiosa. Salma Ferraz relaciona a passagem na qual o narrador fala da vida cotidiana de Maria com um vilancete da lírica camoniana: Descalça vai para a fonte. ${ }^{38}$ O narrador diz: "Descalça vai Maria à fonte, descalça vai ao campo". Na interpretação de Ferraz o sentido dado por Saramago a este texto difere muito do soneto de Camões, uma vez que no poema de Camões a mulher é enaltecida em sua meiguice e simplicidade e no romance a figura de Maria é dessacralizada, ela é enquadrada na categoria das mulheres "que com qualquer coisa se contentam". ${ }^{39}$ O intertexto, mais uma vez, corrobora com a ruptura de uma tradição estabelecida pelo texto bíblico.

\footnotetext{
36 SARAMAGO, 1997. p. 20.

37 TRICCA, 1995. p. 9.

${ }^{38}$ FERRAZ, 1996. p. 31.

39 SARAMAGO, 1997. p. 31.
} 
Essas transgressões efetuadas no texto não deixam de remeter ao conceito de carnavalização estabelecido por Bakhtin, que o vê, na literatura, como um elemento subversivo, que "rompe com a autoridade e introduz alternativas". ${ }^{40}$ Os intertextos utilizados acentuam a carnavalização no texto de Saramago, ao questionar hierarquias e inverter as categorias de sagrado e profano. Termos como heteroglossia e polifonia, que definem a simultaneidade de vozes e diálogos que governam a operação de sentido no texto, segundo Hoquist ${ }^{41}$ também são pertinentes para compreender a função dos intertextos no romance. Uma referência explicita às vozes do texto é feita no episódio da barca. Jesus, Deus e o Diabo estão reunidos num barco, discutindo sobre os propósitos de Deus ao apresentar Jesus como seu filho. Em meio ao diálogo travado entre as três personagens mistura-se uma quarta voz, respondendo a pergunta feita pelo diabo: quem vai criar o Deus inimigo? "Talvez este Deus e o que há-de vir não sejam mais do que heterônimos, De quem, de quê, perguntou curiosa outra voz, De Pessoa... ${ }^{42}$ Essa voz alude ao poeta português Fernando Pessoa e seus heterônimos, suas vozes desdobradas em sua criação literária. No entender de Salma Ferraz, a referência a Pessoa acentua "a carnavalização do texto, pois o narrador está tentando dizer ao leitor que o Diabo talvez seja um mero Heterônimo de Deus, criado por ele, sem nenhuma condição de livrar-se da maldade despótica e sanguinária de seu criador", ${ }^{43}$ o que não pode deixar de ser visto como uma interpretação bastante subversiva da figura de Deus. No mosaico intertextual composto por Saramago no romance, ocorre simultaneamente a absorção, transformação e replicação dos textos, sempre em uma perspectiva de descanonização do texto bíblico, numa operação que, em termos bakhtinianos configura-se como essencialmente dialógica.

\footnotetext{
${ }^{40}$ CUDDON, 1992. p. 121.

${ }^{41}$ HOLQUIST, 1990. p. 69.

${ }^{42}$ SARAMAGO, 1997. p. 389.

${ }^{4}$ FERRAZ, 1996. p. 35.
} 


\section{Referências Bibliográficas}

BARTHES, Roland. S/Z. Trad. Richard Miller. New York: Hill \& Wang, 1974.

BÍBliA Sagrada. A. T. Cântico dos cânticos. 90. ed. São Paulo: Ave Maria, 1993. cap. 2, 5, p. 827 .

BÍBlIA Sagrada. N. T. Evangelho segundo João. 90. ed. São Paulo: Ave Maria, 1993. cap. 11, 43, p. 1400.

CUDDON, J. A. Dictionary of Literary Terms and Literary History. London: Penguin, 1991.

FERRAZ, Salma. Confluências textuais no (Des)Evangelho segundo José Saramago. Uniletras, Ponta Grossa, n. 18, p. 23-36, dez. 1996.

FLORES, Maria da C. de M. G. M. Do mito ao romance: uma leitura de $O$ Evangelho Segundo Jesus Cristo. 1999. Dissertação (Mestrado em Literatura Comparada) - Universidade Federal do Rio Grande Norte, Natal.

GENETTE, Gérard. Palimpsestes: la littérature au second degré. Paris: Editions du Seuil, 1982.

HOLQUIST, Michael. Dialogism: Bakhtin and his world. London, New York: Routledege, 1990.

RIFFATERRE, Michael. Compulsory reader response: the intertextual drive. In: WORTON, Michel; STILL, Judith (Ed.) Intertextuality: theories and practices. Manchester: Manchester University Press, 1993. p. 56-78.

SARAMAGO, José. O Evangelho Segundo Jesus Cristo. 15. reimpr. São Paulo: Companhia das Letras, 1997.

WORTON, Michel; STILL, Judith (Ed.). Intertextuality: theories and practices. Manchester: Manchester University Press, 1993.

TRICCA, Maria Helena de Oliveira (Comp.). Apócrifos: os proscritos da Bíblia. São Paulo: Mercuryo, 1989. 


\section{Resumo}

O Evangelho Segundo Jesus Cristo, de José Saramago, é uma reescrita ficcionalizada da vida de Jesus, fazendo do texto bíblico seu intertexto mais óbvio e direto. O romance, porém, não dialoga apenas com os Evangelhos: Saramago apresenta ao leitor um verdadeiro mosaico de citações e referências, que, uma vez recontextualizadas operam, na maioria das vezes, como elementos de ruptura e subversão em relação à mensagem doutrinária da Bíblia. Essa transgressão, em termos literários, remete tanto ao conceito bakhtiniano de carnavalização, como efetua uma crítica da história e dos preceitos judaicos e cristãos, num contexto mais amplo.

\section{Abstract}

O Evangelho Segundo Jesus Cristo is a fictionalized rewriting of Jesus' story based on the Bible. The novel, although, does not dialog only with the Bible. Saramago shows the reader a mosaic of allusions, quotations and references that, once recontextualized, work mostly to subvert the message conveyed in the canonical gospels, conferring an opposite and satiric meaning in relation to the biblical intertext. Such transgression leads, in literary terms, to the concept of carnivalization established by Bakhtin as well as a clear critic of Jewish and Christian history and premises, within a broader context. 